\title{
Local versus landscape-scale effects of anthropogenic land-use on forest species richness
}

\author{
G. Buffa*, S. Del Vecchio, E. Fantinato, V. Milano \\ Department of Environmental Sciences, Informatics and Statistics (DAIS), Ca' Foscari University of Venice, Via Torino 155, 30172 Venice, Italy
}

\section{ART ICLE INFO}

\section{Keywords:}

Anthropogenic land-use

Ancient forest species

Biodiversity monitoring

Surrogate species

Scale

\begin{abstract}
A B S T R A C T
The study investigated the effects of human-induced landscape patterns on species richness in forests. For 80 plots of fixed size, we measured human disturbance (categorized as urban/industrial and agricultural land areas), at 'local' and 'landscape' scale (500 $\mathrm{m}$ and $2500 \mathrm{~m}$ radius from each plot, respectively), the distance from the forest edge, and the size and shape of the woody patch. By using GLM, we analyzed the effects of disturbance and patch-based measures on both total species richness and the richness of a group of specialist species (i.e. the 'ancient forest species'), representing more specific forest features. Patterns of local species richness were sensitive to the structure and composition of the surrounding landscape. Among the landscape components taken into account, urban/industrial land areas turned out as the most threatening factor for both total species richness and the richness of the ancient forest species. However, the best models evidenced a different intensity of the response to the same disturbance category as well as a different pool of significant variables for the two groups of species. The use of groups of species, such as the ancient forest species pool, that are functionally related and have similar ecological requirements, may represent an effective solution for monitoring forest dynamics under the effects of external factors. The approach of relating local assessment of species richness, and in particular of the ancient forest species pool, to land-use patterns may play an important role for the science-policy interface by supporting and strengthening conservation and regional planning decision making.
\end{abstract}

\section{Introduction}

Forest ecosystems are considered among the most important global repositories of terrestrial biodiversity (Liang et al., 2016). Forests contribute more than any other terrestrial ecosystems to climate relevant cycles and processes, at local, national, and global level. Forests also provide essential ecosystem services, like carbon storage, hydrological protection, air and water purification, improvement of urban and peri-urban living conditions and amenity values such as aesthetic enjoyment and recreation (Costanza et al., 1997; Pearce, 2001). Despite substantial efforts to support the preservation and sustainable use of forest biodiversity, in many industrialized countries, forests are often isolated patches embedded in an anthropogenic matrix, mostly represented by agricultural and built-up areas, which are the dominant elements of the landscape. Anthropogenic activities, such as agriculture, industry and urbanization, have been recognized as major drivers of biodiversity loss worldwide, exerting profound effects on the structure and function of remnant natural ecosystems (Del Vecchio et al., 2015; Guirado et al., 2006; Lindenmayer and Likens, 2011; Matson et al., 1997; Millennium Ecosystem Assessment, 2005; Newbold et al., 2015; Tilman et al., 2001).

Human-induced landscape-level transformations directly affect forest ecosystems by reducing available space for their development and permanence, and fragmenting the remnant patches (Amici et al., 2015; Liu et al., 2003). Due to the adjacency of non-forest habitats, fragmentation has also indirect effects, such as changes in light availability (Cayuela et al., 2009) or wind influences (Svensson et al., 2010). Both direct and indirect effects lead to environmental deterioration and decreased habitat quality (Kinzig and Grove, 2001; Wei and Hoganson, 2005).

In recent decades, several studies have identified such spatial attributes of landscape elements as their size, shape, and extent as influencing population processes and the richness and composition of assemblages (Fischer and Lindenmayer, 2007; McKinney, 2008; Steffan-Dewenter and Tscharntke, 2000). Species richness, in particular, has been repeatedly linked to the spatial characteristics of ecosystems and has proved to be particularly sensitive to the influence of human land-use (Jentsch et al., 2012; McKinney, 2008), thereby being identified as an essential tool for biodiversity monitoring (Bitencourt et al., 2016; Del Vecchio et al., 2016; Janišová, 2014).

One problem that arises in such research is the scale dependence of both diversity and disturbance, namely they can depend on the scales at which they are sampled. The striking role of the scale has been well recognized, becoming one of the unifying concepts in ecology (Van Dobben and Lowe-McDonnel, 1975; Wiens, 1989), concerning all organizational levels (from individuals to ecosystems). It represents a primary issue in the interpretation of environmen-

\footnotetext{
* Corresponding author.

Email address: gabriella.buffa@unive.it (G. Buffa)
} 
tal heterogeneity (Battisti and Fanelli, 2015; Levin, 1992; O'Neill et al., 1991), since different patterns can be revealed by different spatial scales of observation (Hanke et al., 2014). Moreover, such habitat properties as composition and structure may arise from the interaction of both coarse landscape- and fine local-scale filters (Buffa et al., 2007; Dale, 1999; Gigante et al., 2016b; Lortie et al., 2004), i.e. in addition to local physical and biotic factors, the response of a population to disturbance can also be influenced by larger-scale phenomena (Hanski, 1998). Thus, although no preferred scale exists (Levin, 1992), the scale at which environmental patterns are quantified influences the result (Turner et al., 2001; Wiens, 1989; Wu, 2004) and inappropriate scales may fail in detecting patterns ( $\mathrm{Li}$ and $\mathrm{Wu}, 2004$ ).

However, several studies evidence that the importance of environmental, external factors strongly differs not only across spatial scales but also among taxonomic groups (Laurance et al., 2002; Polyakova et al., 2016; Turtureanu et al., 2014). Dauber et al. (2003) further suggested that species richness patterns of different species groups are often not correlated and their dependence on the landscape pattern varies among groups. These studies consistently indicate that environmental changes both at local and landscape scales do not affect all species and taxa equally, but the effects depend on species traits. Arguably, different groups of species can respond in a different way to a given event, or respond to different events or to different intensities of the same event. Especially for species which do not possess evolutionary adaptations enabling them to cope with large scale disturbance, anthropogenic changes may have a much more dramatic effect relative to other species (Honnay et al., 2005). As for forest ecosystems, species such as forest floor plant species, and in particular the ancient forest species, suffer increased extinction probability compared to other forest species, due to their biological and ecological characteristics. Their common features are slow growth, long life-cycle, stress tolerant strategy, early and short flowering, a strong vocation for vegetative propagation, heavy seeds and transient seed bank (Verheyen et al., 2003), limited dispersal power in space and low colonization ability (Buffa and Villani, 2012). Being restricted to a narrow range of ecological requirements, ancient forest species are highly specialized, i.e. species strictly associated with the interior, more protected and undisturbed part of a forest (Hermy, 1994), and therefore indicative of more original forest conditions (Peterken, 1974). Ancient forest species thus meet qualitative (forest quality) as well as quantitative (diversity) conservation criteria (Hermy et al., 1999). Specialist species define the habitat identity, and have a prominent role in assuring the maintenance of its structure and functionality (Del Vecchio et al., 2016; Fantinato et al., 2016; Godefroid and Koedam, 2003). This is particularly important since their extinction may have consequences on the whole ecosystem, leading to ecosystems collapse (Keith et al., 2013), even if the number of specialist species is usually small compared to the total number of species in a habitat. Since specialist species are experiencing higher extinction risk relative to generalist species (Buffa and Villani, 2012; Clavel et al., 2011; Fantinato et al., 2017; Rooney et al., 2004; Slaviero et al., 2016), their presence can be used as a synthetic indicator of the status of a habitat, or fine-filter surrogate species which represent more specific habitat features (Jones et al., 2016; Rodrigues and Brooks, 2007). If attentively selected, specialist species can thus be more effective in describing the relationship between disturbance patterns and biodiversity than the use of total species richness.

Aim of the present paper was to investigate the effects of human-induced landscape patterns on species richness in forests. In particular, we analyzed the trends of total species richness and the richness of the ancient forest species pool and tested if total species richness and the richness of the ancient forest species pool respond in a different way to the disturbance generated by human activities. To evaluate the relationship between local plant species richness and landscape variables, while taking into account the effects of changing extent, we measured human disturbance at two spatial scales, at 'local' $(500 \mathrm{~m}$ radius from the central point of each plot) and at 'landscape' scale ( $2500 \mathrm{~m}$ radius).

\section{Methods}

\subsection{Study area}

The study was conducted in the hilly sector of the Veneto Region (north-eastern Italy). The study area is a historically cultivated landscape, where human activities created a complex landscape where ecological, socioeconomic, and cultural patterns governed the presence, distribution, and abundance of wild species assemblages. Over the last 40 years, the human component has been increasingly dominating in space and time, and the area has faced dramatic land-use changes which include the conversion of complex natural ecosystems to simplified managed ecosystems, and the intensification of resource use, leading to the loss of biodiversity in pristine habitats and traditional, low-intensity agro-ecosystems. New disturbance regimes have transformed the traditional landscape, which is nowadays dominated by land-uses such as cereal cropping, vineyards, horticulture, and tree plantations. Natural and semi-natural habitats such as forests, grasslands and hedgerows, are interspersed with human settlements, roads, and trenches, making the landscape increasingly prone to the risks of rapid biological impoverishment. The remnant forest vegetation is mainly composed of mesophilous broad-leaved deciduous oak forest communities. The tree layer is dominated by Quercus robur L., Q. cerris L., Fraxinus ornus L., Acer campestre L., and Carpinus betulus L.. Locally, termophilous deciduous woods dominated by $Q$. pubescens Willd., and meso-hygrophilous deciduous forests dominated by Alnus spp. can also be found. Other traditional rural landscape components are mesophilous and dry grasslands.

\subsection{Data collection}

To allow inference about how landscape composition, i.e. the types of different land-uses and their relative proportion, influences species richness and composition in forest remnants, we surveyed 80 georeferenced plots with a fixed surface $(8 \times 8 \mathrm{~m})$. A preliminary forest stand stratification was conducted according to elevation range (from 100 to $300 \mathrm{~m}$ a.s.l.) and bedrock types (neutro-basic limestone) which allowed the identification of 59 patches of mesophilous broad-leaved deciduous oak forest communities, with patch surface ranging from 0.08 to 350 ha. In order to achieve a homogenous and proportional distribution of the plots within the patches, we randomly created 80 points (function "Create Random Points" in ArcGIS 9.3), specifying a minimum of 1 and a maximum of 5 points per patch (see Appendix 1).

In each plot, all vascular plant species in each vertical layer were recorded.

For each plot we calculated total species richness and the richness of ancient forest species. Ancient forest species, characterizing the herb layer, were defined according to a previous study by Buffa and Villani (2012), in which they have been identified based on life history traits such as morphology (life form), life-cycle, floral and reproductive biology (type of reproduction - vegetative, sexual or both, pollen vector, dispersal mode), and ecological strategy (Grime, 1979; Pierce et al., 2017). Ancient forest species of studied forests have some common traits, such as a strong vocation for vegetative reproduction and ants as preferential dispersal agent. They occupy two different temporal and spatial niches: nearly $50 \%$ are small spring geophytes, CSR strategists, with entomophilous pollination (e.g. Anemone sp.pl., Cardamine bulbifera (L.) Crantz, Lathyrus vernus (L.) Bernh., Polygonatum multiflorum (L.) All.). The other $50 \%$ is represented by higher hemicryptophytes, with CS strategy (e.g. Carex sylvatica Huds., Melittis melissophyllum L., Primula vulgaris Huds., Pulmonaria officinalis L.).

The structure and composition of the landscape surrounding each plot was derived from a high-resolution land-use map (scale 1:10,000), extracted from the Corine Land Cover map level III (ISPRA, 2010). Human disturbance was defined as the proportion of land area converted by humans (Mayor et al., 2015), and was categorized as agricultural (e.g. pasture and croplands, tree planting areas), and urban/ industrial (e.g. urban and rural settlements, roads and railways, green urban areas, leisure facilities). To quantify the effects of in- 
creasing extent, for each plot, human disturbance was measured at two scales: 'local scale' and 'landscape scale', in two circular buffers, with a radius of $500 \mathrm{~m}$ and $2500 \mathrm{~m}$ from the central point of each plot respectively. The two scales were chosen among other intermediate possible scales because disturbance measured at these two scale resulted the least correlated $(r=0.487)$. In each buffer, the proportion of land area covered by forests was used as a proxy measure of the connectivity among natural patches.

For each plot, we also determined patch-based measures of pattern including the distance from the forest edge (measured as the distance in $\mathrm{m}$ from the nearest forest edge; function "Near" in ArcGIS 9.3), size and shape of the woody patch in which each plot was included. To figure out the shape of the patch we used a compactness index (Bosch, 1978; Davis, 1986), according to the formula:

$\mathrm{K}=\frac{2 \sqrt{\pi A}}{P}$

where $\mathrm{A}$ is the area $\left(\mathrm{m}^{2}\right)$ and $\mathrm{P}$ is the perimeter of the patch. This index provides a dimensionless number that represents the degree to which a shape is compact. When the value of $\mathrm{K}$ tends to 0 , it indicates an elongated and irregular shape, while when it tends to 1 , it indicates a circular and regular shape.

\subsection{Data analysis}

To investigate the effects of the landscape and patch-based variables on total species richness and richness of ancient forest species, we performed generalized linear models. The proportion of agricultural, urban/industrial, forested area and patch configuration measures (size, shape and distance from the edge) were used as predictor variables. Total species richness and richness of ancient forest species were used as response variables. The effects of disturbance were tested at both local and landscape scale. For each model we used the Poisson error distribution. To simplify the models we performed a stepwise algorithm of explanatory variables (backward selection). The Akaike Information Criterion (AICc; R package MASS; Venables and Ripley, 2002) was used to select the best model. According to the procedure, models explaining most variance with a lower number of predictors have smallest AIC and are considered 'best models' (Burnham and Anderson, 2002). The best fitting models procedure led to exclude the proportion of forested area since it resulted correlated to the proportion of agricultural land area (Pearson correlation; local scale: $r=-0.81$; Landscape scale: $r=-0.73$ ).

\section{Results}

In total, 239 plant species were recorded, of which 57 were classified as ancient forest species. Mean total species richness per plot was $16.8 \pm 5.2$, while the mean richness of ancient forest species was $3.1 \pm 2.1$. The most common ancient forest species were mostly geophytes such as Allium ursinum L., Anemone nemorosa L., A. trifolia L., Cardamine bulbifera, Erythronium dens-canis L., Hepatica nobilis Schreb., and Polygonatum multiflorum. Among hemicryptophytes, the most common were Brachypodium sylvaticum (Huds.) P. Beauv., Carex sylvatica, Epimedium alpinum L., and Salvia glutinosa L..

The average patch size was $57.94 \mathrm{ha} \pm 92$, but many patches $(46.83 \%)$ were small (surface $<15$ ha). Most forest fragments $(70 \%)$ had an irregular shape (shape index $<0.50$ ), with an average value of $0.40 \pm 0.21$ (median of 0.37). The distance of plots from the nearest forest edge ranged from 0.22 to $167.29 \mathrm{~m}$ (median of $22.26 \mathrm{~m}$ ). Agriculture was basically the dominant land-use type at landscape scale, with a mean proportion of $72.9 \pm 15.5$, ranging from $31.7 \%$ to $100 \%$. Conversely, at local scale the agricultural land area exhibited the full continuum of $0-100$ percent (mean proportion $66.6 \% \pm 28.8$ ). Urban/industrial surface ranged from $2.0 \% \pm 7.4$ at local to $6.9 \% \pm 7.6$ at landscape scale. The proportion of forested land area was always low and de-
The selection of the best fitting models $\left(\Delta_{\text {AIC }}\right.$ total richness $=-8.9$; $\Delta_{\text {AIC }}$ ancient forest species richness $=-6.06$ ) indicated that, at local scale, none of the selected predictor variables (proportion of agricultural and urban/industrial, and patch-configuration measures) had a significant role in determining neither the total species richness nor the ancient forest species richness.

At landscape scale, the best models included the proportion of urban/industrial land area for both total species richness and the richness of ancient forest species. In both cases with a highly significant negative effect. However, if we consider the trendlines, which represent how the richness decreases with increasing urban/industrial land area, the models showed a stronger effect on the richness of ancient forest species (Table 1). Total species richness was also negatively influenced by the proportion of agricultural land area, while for ancient forest species richness, the model evidenced the significant positive role of a compact shape (Table 1 and Fig. 1).

\section{Discussion}

Our study demonstrates that patterns of local species richness in forest ecosystems are sensitive to the structure and composition of the surrounding landscape. Our results are consistent with several previous studies (e.g., Amici et al., 2015; Bennett et al., 2006; Collingham et al., 2000; Fahrig, 2003; Godefroid and Koedam, 2003; Murcia, 1995; Tilman, 1994) underlining the importance of the landscape context in shaping the richness and composition of local habitat species assemblages. Especially, according to Newbold et al. (2015), rural and urban areas, which constitute the two main land-use categories associated with human activities, can reduce species richness by more than half in the worst-affected habitats.

The observed pattern showed a similar negative trend of both total species richness and the richness of ancient forest species. Nevertheless, the best models evidenced a different intensity of the response to the same disturbance category as well as a different pool of variables for the two groups of species, i.e. the ancient forest species pool responded differently to small scale (patch-level measures) characteristics and large-scale (landscape) features. Although always present with a lower proportion relative to agricultural land-use, urban/industrial land area proved to have a strong negative influence on the richness of ancient forest species. Arguably, human settlements differ in their structural features compared to rural areas. Containing remnant patches of natural or semi-natural surfaces (Evans et al., 2009), rural areas can provide temporary surrogate habitats for some species, thereby favoring the permanence of the relationships between individuals, populations, and wild species assemblages. For example, man-made linear elements marking boundaries, like hedges, lines of trees, and grass strips, are particularly widespread in farmed landscape throughout temperate regions (Baudry et al., 2000), and may play a vital role in delivering ecosystem services (Lindborg et al., 2014). For example, Dainese et al. (2017) found that the presence of hedgerows in the landscape enhanced potential pollination, both in terms of visitation rate and seed set. Hedgerows can thus act as transitory surrogate habitats for forest species (Ernoult and Alard, 2011; Morelli, 2013). This assumption is confirmed by Masin et al. (2009) who reported the presence in the region of some ancient forest species (e.g. Anemone sp.pl., Allium ursinum, Circaea lutetiana L., Polygonatum multiflorum) outside the forests, along the oldest hedgerows, thereby strengthening the important role of spread hedgerows and other connecting elements in facilitating the movement of organisms. Conversely, the nature of urban/ industrial land-use normally involves both a net loss of natural and semi-natural surfaces, thus reducing the area available for wild plants and animals (Auffret et al., 2015; McKinney, 2008), and a structural simplification of vegetation in many areas. Landscaping and the maintenance of residential, commercial and industrial areas typically entail removal of woody plants (e.g. hedges, small woods) and an increase in green urban areas such as lawns (Marzluff, 2001), resulting in the loss of surrogate habitats and increased isolation of ancient forest species populations. Further, forests directly bordering, or near to, human settlements are likely more prone to suffer higher intensity of disturbance due to open-air leisure activities such as walk- 
Table 1

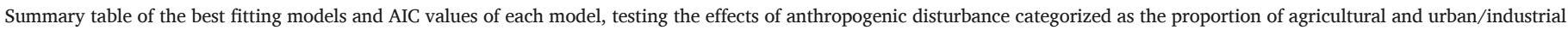
land areas, and patch-based variables (size, shape and the distance from the forest edge), on total species richness and the richness of ancient forest species.

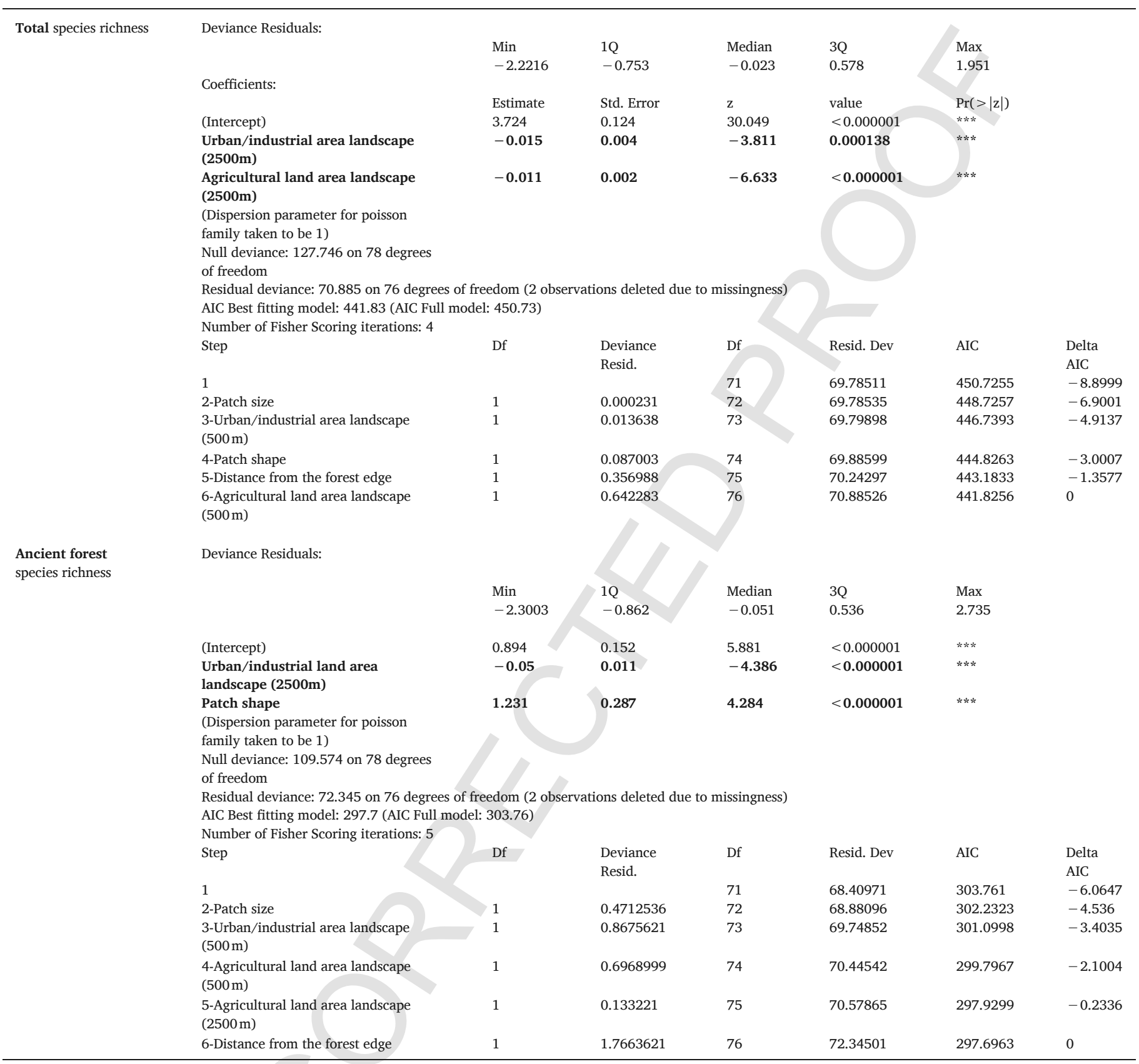

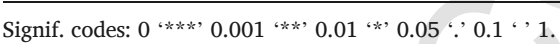

local direct human disturbance. All of these factors tend to increase with urbanization intensity (Hahs and McDonnell, 2006) and combine to reduce both habitat core area and the overall habitat quality.

Contrary to total species richness, for which no patch-level measure emerged as significant, ancient forest species responded positively to the patch shape, i.e. the richness of ancient forest species increased with increasing regularity of the shape. The positive effect of a regular shape on species richness has already been shown and related to the edge effect that in highly disturbed landscapes may become much more important than area and isolation (Harrison and Bruna, 1999; Gonzalez et al., 2010; Turner et al., 1996). For an identical area, an irregular forest fragment has a higher edge/core ratio than a compact forest fragment, namely a smaller undisturbed core area suitable for the persistence of specialist species (Dauber et al., 2003). Conversely, the best model did not retain the distance from the edge. This result is in accordance with Guirado et al. (2006) who found that forest species of small patches were not affected by the distance from the edge. This effect, somehow unexpected, could be due to either a non-linear responses of species richness and composition to the distance
Alaback, 2004) or to the configuration of patch edges linked to the forestry regimes, e.g. the presence of buffer zones that minimize the effect of a short distance from the edge.

The ancient forest species pool seems not to be affected by decreasing patch area. Several studies (e.g., Buffa and Villani, 2012; Dupré and Ehrlén, 2002; Kolb and Diekmann, 2005) suggested that patch area can become a secondary factor compared to species-specific life-history traits and habitat quality. Moreover, the effect of the patch area might change because of direct or indirect effects of human activities (Bennett et al., 2004; Honnay et al., 1999), especially in urban and peri-urban contexts (Guirado et al., 2006; Moffatt et al., 2004). Arguably, having short distance seed dispersal mechanisms, and spreading mostly vegetatively by stolons or rhizomes (Buffa and Villani, 2012; Honnay et al., 2002), ancient forest species likely benefit mostly from a high patch quality rather than from large areas per se. However, several studies (e.g. Buffa and Villani, 2012; Cousins, 2009; Ovaskainen and Hanski, 2002) evidenced that in long-lived species the negative consequences of fragmentation (e.g. reduced area and population size, and increased isolation) may become visible after a long time, caus- 
Total species richness
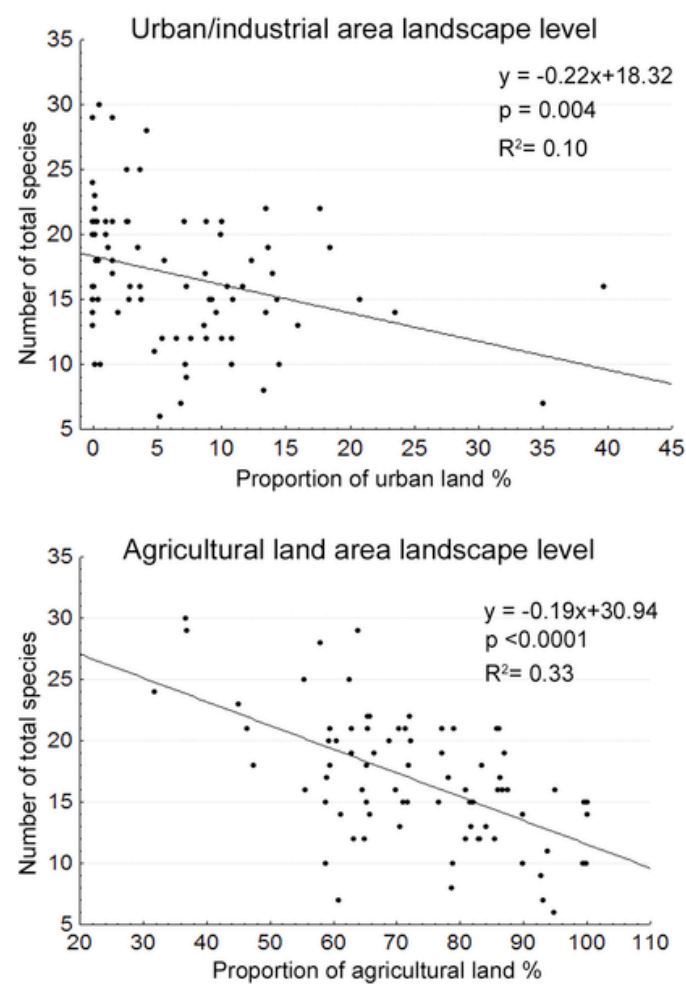

Ancient forest species richness
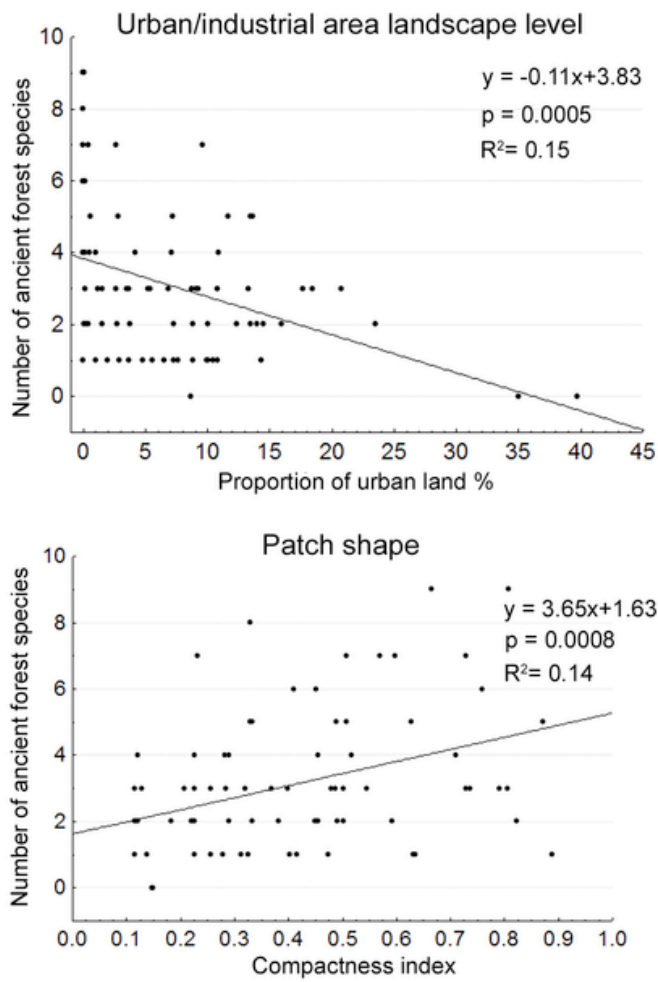

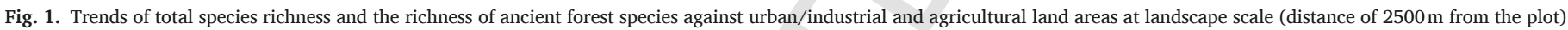
and the patch shape.

habitats (see e.g. Kuussaari et al., 2009 for a review). In this regard, we have to consider that the ancient forest species richness we detected could not be in equilibrium and that species will go extinct until the ancient forest species richness reaches a new equilibrium.

The different behavior of ancient forest species compared to total species richness evidences that, although often used as indicator of ecosystem change, total species richness can be less able to reveal patterns underlying forests change. The use of groups of species, such as the ancient forest species pool, that are functionally related and have similar ecological requirements, may represent an effective solution for describing forest dynamics under the effects of external factors.

The use of groups of species as surrogates for the overall biodiversity has been given significant attention in recent times, due to its potential contribution to the simplification of data requirements for monitoring and conservation planning (Gigante et al., 2016a; Larsen et al., 2009; Leal et al., 2010). The assumption at the basis of this approach is that if threats faced by specialist species are effectively detected and managed, threats to all other species will also be effectively managed (Jones et al., 2016). Although the use of indicator species has been criticized (e.g. Lawton et al., 1998) for possible drawbacks such as the need of specific information for each site and the difficulty to standardize the survey method, the concept of indicator species remains an appealing one and potentially a powerful management tool because of the impossibility of monitoring everything (Lindenmayer et al., 2000). Moreover, as stated by Moffatt and McLachlan (2004), the presence of indicator species could be easily established at each site, thereby allowing managers to accurately assess the quality of forests without requiring an exhaustive description of the understorey. Indeed, understorey herbs have been already used as operative indicators of deciduous forest regeneration (McLachlan and Bazely, 2001), restoration of forest plantations (Honnay et al., 2002), long-term continuity of boreal forests (Ohlson et al., 1997), impact of forest management (Scolastri et al., 2017), and riparian forest disturbance (Moffatt and McLachlan, 2004).

Finally, biodiversity conservation policies and monitoring programs should take into account the crucial role of the landscape scale in predicting of local species assemblages. A lack of awareness of the close interrelation among patterns that occur at different spatial scales may cause flaws and failures in conservation strategies or actions implemented at the local scale. Such an approach of relating local assessment of ancient forest species richness to land-use patterns may thus play an important role for the science-policy interface by supporting and strengthening forest conservation and regional planning decision making.

\section{Author contribution}

GB conceived the idea and design of the study and wrote the manuscript, SDV, EF, conducted field work, data analysis and collaborated in the writing, VM collaborated in field work.

Appendix 1. Distribution of the 80 plots randomly generated by means of the function Create Random Points" in ArcGIS 9.3. To achieve a homogenous and proportional distribution of the plots within the 59 patches, points were randomly created specifying a minimum of 1 and a maximum of 5 points per patch

\begin{tabular}{lll}
\hline patch id & patch area (ha) & n. of random plots \\
\hline 1 & 0.084 & 1 \\
2 & 87.676 & 4 \\
3 & 13.195 & 1 \\
4 & 1.773 & 1 \\
5 & 1.313 & 1 \\
6 & 2.652 & 1 \\
7 & 8.425 & 1 \\
8 & 0.299 & 1 \\
9 & 11.486 & 2 \\
10 & 23.463 & 1 \\
11 & 4.895 & 1 \\
12 & 25.872 & 2 \\
\hline
\end{tabular}




\begin{tabular}{|c|c|c|}
\hline 13 & 3.774 & 1 \\
\hline 14 & 7.33 & 1 \\
\hline 15 & 17.019 & 2 \\
\hline 16 & 1.502 & 1 \\
\hline 17 & 17.819 & 1 \\
\hline 18 & 6.774 & 1 \\
\hline 19 & 7.797 & 1 \\
\hline 20 & 0.544 & 1 \\
\hline 21 & 92.353 & 3 \\
\hline 22 & 43.292 & 2 \\
\hline 23 & 2.241 & 1 \\
\hline 24 & 41.999 & 1 \\
\hline 25 & 4.539 & 2 \\
\hline 26 & 347.993 & 5 \\
\hline 27 & 36.9 & 1 \\
\hline 28 & 6.148 & 2 \\
\hline 29 & 1.282 & 1 \\
\hline 30 & 6.057 & 2 \\
\hline 31 & 7.833 & 1 \\
\hline 32 & 0.487 & 1 \\
\hline 33 & 63.192 & 1 \\
\hline 34 & 16.931 & 1 \\
\hline 35 & 21.478 & 1 \\
\hline 36 & 4.018 & 1 \\
\hline 37 & 3.375 & 1 \\
\hline 38 & 11.442 & 1 \\
\hline 39 & 0.089 & 1 \\
\hline 40 & 1.445 & 1 \\
\hline 41 & 30.941 & 1 \\
\hline 42 & 224.186 & 1 \\
\hline 43 & 18.607 & 1 \\
\hline 44 & 1.805 & 1 \\
\hline 45 & 23.901 & 1 \\
\hline 46 & 12.154 & 1 \\
\hline 47 & 232.818 & 5 \\
\hline 48 & 38.77 & 1 \\
\hline 49 & 199.218 & 1 \\
\hline 50 & 3.828 & 1 \\
\hline 51 & 37.715 & 1 \\
\hline 52 & 5.867 & 1 \\
\hline 53 & 62.083 & 2 \\
\hline 54 & 32.938 & 1 \\
\hline 55 & 27.817 & 1 \\
\hline 56 & 24.588 & 1 \\
\hline 57 & 21.816 & 1 \\
\hline 58 & 8.297 & 1 \\
\hline 59 & 14.089 & 1 \\
\hline
\end{tabular}

\section{(1)}

Cayuela, L., Murcia, C., Hawk, A.A., et al., 2009. Tree responses to edge effects and canopy openness in a tropical montane forest fragment in southern Costa Rica. Trop. Conserv. Sc 2, 425-436.

Clavel, J., Julliard, R., Devictor, V., 2011. Worldwide decline of specialist species: toward a global functional homogenization?. Front. Ecol. Environ. 9, 222-228.

Collingham, Y.C., Wadsworth, R.A., Huntley, B., et al., 2000. Predicting the spatial distribution of non-indigenous riparian weeds: issues of spatial scale and extent. J. Appl. Ecol. 37, 13-27.

Costanza, R., d'Arge, R., de Groot, R., et al., 1997. The value of the world's ecosystem services and natural capital. Nature 387, 253-260.

Cousins, S.A.O., 2009. Extinction debt in fragmented grasslands: paid or not?. J. Veg. Sci. 20, 3-7.

Dainese, M., Montecchiari, S., Sitzia, T., et al., 2017. High cover of hedgerows in the landscape supports multiple ecosystems services in Mediterranean cereal fields. J. Appl. Ecol. 54 (2), 380-388.

Dale, M., 1999. Spatial Pattern Analisys in Plant Ecology. Cambridge University Press, Cambridge.

Dauber, J., Hirsch, M., Simmering, D., et al., 2003. Landscape structure as an indicator of biodiversity: matrix effects on species richness. Agric. Ecosyst. Environ. 98, 321-329.

Davis, J., 1986. Statistics and Data Analysis in Geology. John and Wiley Sons, New York.

Del Vecchio, S., Pizzo, L., Buffa, G., 2015. The response of plant community diversity to alien invasion: evidence from a sand dune time series. Biodivers. Conserv. 24, 371-392.

Del Vecchio, S., Slaviero, A., Fantinato, E., Buffa, G., 2016. The use of plant community attributes to detect habitat quality in coastal environments. AoB PLANTS 8, plw40.

Dupré, C., Ehrlén, J., 2002. Habitat configuration, species traits and plant distributions. J. Ecol. 90, 796-805.

Ernoult, A., Alard, D., 2011. Species richness of hedgerow habitats in changing agricultural landscapes: are $\alpha$ and $\gamma$ diversity shaped by the same factors?. Landsc. Ecol. 26, 683-696.

Evans, K.L., Newson, S.E., Gaston, K.J., 2009. Habitat influences on urban avian assemblages. Ibis 151, 19-39.

Fahrig, L., 2003. Effects of habitat fragmentation on biodiversity. Annu. Rev. Ecol. Evol. Systemat. 34, 487-515.

Fantinato, E., Del Vecchio, S., Slaviero, A., et al., 2016. Does flowering synchrony contribute to the sustainment of dry grassland biodiversity?. Flora 222, 96-103.

Fantinato, E., Del Vecchio, S., Baltieri, M., Fabris, B., Buffa, G., 2017. Are food-deceptive orchid species really functionally specialized for pollinators?. Ecol. Res. 32, 951-959.

Fischer, J., Lindenmayer, D.B., 2007. Landscape modification and habitat fragmentation: a synthesis. Global Ecol. Biogeogr. 16, 265-280.

Gigante, D., Attorre, F., Venanzoni, R., et al., 2016a. A methodological protocol for Annex I Habitats monitoring: the contribution of vegetation science. Plant Sociol 53, 77-78.

Gigante, D., Foggi, B., Venanzoni, R., et al., 2016b. Habitats on the grid: the spatial dimension does matter for red-listing. J. Nat. Conserv. 32, 1-9.

Godefroid, S., Koedam, N., 2003. Distribution pattern of the flora in a peri-urban forest: an effect of the city-forest ecotone. Landsc. Urban Plann. 65, 169-185.

Gonzalez, M., Ladet, S., Deconchat, M., et al., 2010. Relative contribution of edge and interior zones to patch size effect on species richness: an example for woody plants. For. Ecol. Manag. 259, 266-274.

Grime, J.P., 1979. Plant Strategies and Vegetation Processes. John Wiley \& Sons, Chichester, New York, Brisbane, Toronto.

Guirado, M., Pino, J., Rodà, F., 2006. Understorey plant species richness and composition in metropolitan forest archipelagos: effects of forest size, adjacent land use and distance to the edge. Global Ecol. Biogeogr. 15, 50-62.

Hahs, A.K., McDonnell, M.J., 2006. Selecting independent measures to quantify Melbourne's urban-rural gradient. Landsc. Urban Plann. 78, 435-448.

Hanke, W., Bohner, J., Dreber, N., et al., 2014. The impact of livestock grazing on plant diversity: an analysis across dryland ecosystems and scales in southern Africa. Ecol. Appl. 24, 1188-1203.

Hanski, I., 1998. Metapopulation dynamics. Nature 396, 41-49.

Harrison, S., Bruna, E., 1999. Habitat fragmentation and large-scale conservation: what do we know for sure?. Ecography 22, 225-232.

Hermy, M., 1994. Effects of former land use on plant diversity and pattern in European deciduous woodlands. Biodiversity, temperate ecosystems, and global change. In: In: Boyle, T.J.B., Boyle, C.E.B. (Eds.), Biodiversity, Temperate Ecosystems, and Global Change, vol 20, NATO ASI Series, pp. 123-144.

Hermy, M., Honnay, O., Firbank, L., Grashof-Bokdam, C., Lawesson, J.E., 1999. An ecological comparison between ancient and other forest plant species of Europe, and the implications for forest conservation. Biol. Conserv. 91, 9-22.

Honnay, O., Pendels, P., Vereecken, H., Hermy, M., 1999. The role of patch area and habitat diversity in explaining native plant species richness in disturbed suburban forest patches in northern Belgium. Divers. Distrib. 5, 129-141.

Honnay, O., Bossuyt, B., Verheyen, K., et al., 2002. Ecological perspectives for the restoration of plant communities in European temperate forests. Biodivers. Conserv. 11, $213-242$.

Honnay, O., Jacquemyn, H., Bossuyt, B., et al., 2005. Forest fragmentation effects on patch occupancy and population viability of herbaceous plant species. New Phytol. 166, $723-736$.

ISPRA, 2010. La realizzazione in Italia del progetto Corine Land Cover 2006, ISPRA, RAPPORTI 131/2010.

Janišová, M., 2014. The role of surrounding landscape in determining species richness of mesic grasslands in Pannonian basin and Carpathian mountains. Appl. Ecol. Environ. Res. 12, 251-266.

Jentsch, A., Steinbauer, M.J., Alt, M., et al., 2012. A systematic approach to relate plant-species diversity to land use diversity across landscapes. Landsc. Urban Plann. 107, 236-244.

Jones, K.R., Plumptre, A.J., Watson, J.E.M., et al., 2016. Testing the effectiveness of surrogate species for conservation planning in the Greater Virunga Landscape, Africa. Landsc. Urban Plann. 145, 1-11.

Keith, D.A., Rodríguez, J.P., Rodríguez-Clark, K.M., et al., 2013. Scientific foundations for an IUCN red list of ecosystems. PLos One 8, 1-25. 
Kinzig, A., Grove, J., 2001. Urban-suburban ecology. In: Levins, S.A. (Ed.), The Encyclopedia of Biodiversity. Academic Press, San Diego.

Kolb, A., Diekmann, M., 2005. Effects of life-history traits on responses of plant species to forest fragmentation. Conserv. Biol. 19, 929-938.

Kuussaari, M., Bommarco, R., Heikkinen, R.K., Helm, A., Krauss, J., Lindborg, R., Ockinger, E., Partel, M., Pino, J., Roda, F., Stefanescu, C., Teder, T., Zobel, M., Steffan-Dewenter, I., 2009. Extinction debt: a challenge for biodiversity conservation. Trends Ecol. Evol. 24, 564-571.

Larsen, F.W., Bladt, J., Rahbek, C., 2009. Indicator taxa revisited: useful for conservation planning?. Divers. Distrib. 15, 70-79.

Laurance, W.F., Lovejoy, T.E., Vasconcelos, H.L., et al., 2002. Ecosystem decay of Amazonian forest fragments: a 22-year investigation. Conserv. Biol. 16, 605-618.

Lawton, J.H., Bignell, D.E., Bolton, B., Bloemers, G.F., Eggleton, P., Hammond, P.M., Hodda, M., Holt, R.D., Larsen, T.B., Mawdsley, N.A., Stork, N.E., Srivastava, D.S., Watt, A.D., 1998. Biodiversity inventories, indicator taxa and effects of habitat modification in tropical forest. Nature 391, 72-76.

Leal, I.R., Bieber, A.G.D., Tabarelli, M., et al., 2010. Biodiversity surrogacy: indicator taxa as predictors of total species richness in Brazilian Atlantic forest and Caatinga. Biodivers. Conserv. 19, 3347-3360.

Levin, S.A., 1992. The problem of pattern and scale in ecology. Ecol. 73, 1943-1967.

Li, H., Wu, J., 2004. Use and misuse of landscape indices. Landsc. Ecol. 19, 389-399.

Liang, J., Crowther, T.W., Picard, N., et al., 2016. Positive biodiversity-productive relationship predominant in global forest. Science 354, aaf8957.

Lindborg, R., Plue, J., Andersson, K., et al., 2014. Function of small habitat elements for enhancing plant diversity in different agricultural landscapes. Biol. Conserv. 169, 206-213.

Lindenmayer, D.B., Likens, G.E., 2011. Direct measurement versus surrogate indicator species for evaluating environmental change and biodiversity loss. Ecosystems 14, $47-59$.

Lindenmayer, D.B., Margules, C.R., Botkin, D.B., 2000. Indicators of biodiversity for ecologically sustainable forest management. Conserv. Biol. 14 (4), 941-950.

Liu, J.G., Daily, G.C., Ehrlich, P.R., et al., 2003. Effects of household dynamics on resource consumption and biodiversity. Nature 421, 530-533.

Lortie, C.J., Brooker, R.W., Choler, P., et al., 2004. Rethinking plant community theory. Oikos 107, 433-438.

Marzluff, L., 2001. Worldwide urbanization and its effects on birds. In: Marzluff, J., Bowman, R., Donnelly, R. (Eds.), Avian Ecology in an Urbanizing World. Kurwer, Norwll, Massachusetts. pp. 19-47.

Masin, R., Bertani, G., Favaro, G., et al., 2009. Annotations on the flora of venice province (NE Italy). Natura Vicentina 13, 5-106.

Matson, P.A., Parton, W.J., Power, A.G., et al., 1997. Agricultural intensification and ecosystem properties. Science 277, 504-509.

Mayor, S.J., Cahill, J.F., He, F.L., et al., 2015. Scaling disturbance instead of richness to better understand anthropogenic impacts on biodiversity. PLos One 10 (5), e0125579.

McKinney, M., 2008. Effects of urbanization on species richness: a review of plants and animals. Urban Ecosyst. 11, 161-176.

McLachlan, S.M., Bazely, D.R., 2001. Recovery patterns of understory herbs and their use as indicators of deciduous forest regeneration. Conserv. Biol. 15, 98-110.

Meng, X.F., Zhang, Z.W., Li, Z., et al., 2015. The effects of city-suburb-exurb landscape context and distance to the edge on plant diversity of forests in Wuhan, China. Plant Biosyst. 149, 903-913.

Millennium Ecosystem Assessment, 2005. Ecosystems and Human Well-being: Biodiversity Synthesis. World Resources Institute, Whashington DC.

Moffatt, S.F., McLachlan, S.M., 2004. Understorey indicators of disturbance for riparian forests along an urban-rural gradient in Manitoba. Ecol. Indic 4, 1-16.

Moffatt, S.F., McLachlan, S.M., Kenkel, N.C., 2004. Impacts of land use on riparian forests along urban-rural gradient in southern Manitoba. Plant Ecol. 174, 119-135.

Morelli, F., 2013. Relative importance of marginal vegetation (shrubs, hedgerows, isolated trees) surrogate of HNV farmland for bird species distribution in Central Italy. Ecol. Engin 57, 261-266.

Murcia, C., 1995. Edge effects in fragmented forests - implication for conservation. Trends Ecol. Evol. 10, 58-62.
Newbold, T., Hudson, L.N., Hill, S.L.L., et al., 2015. Global effects of land use on local terrestrial biodiversity. Nature 520, 45-50.

O'Neill, R., Gardner, R., Milne, B., et al., 1991. Heterogeneity and spatial hierarchies. In: Kolasa, J., Pickett, S. (Eds.), Ecological Heterogeneity. Springer-Verlag, New York, pp. 85-96.

Ohlson, M., Soderstrom, L., Hornberg, G., et al., 1997. Habitat qualities versus long-term continuity as determinants of biodiversity in boreal old-growth swamp forests. Biol Conserv. 81, 221-231.

Ovaskainen, O., Hanski, I., 2002. Transient dynamics in metapopulation response to perturbation. Theor. Popul. Biol. 61, 285-295.

Pauchard, A., Alaback, P.B., 2004. Influence of elevation, land use and landscape context on patterns of alien plant invasions along roadsides in protected areas of south-central Chile. Conserv. Biol. 18, 1-11.

Pearce, D., 2001. Valuing biological diversity: issues and overview. In: Valuation of Biodiversity Benefits: Selected Studies. OECD, Paris, pp. 27-44.

Peterken, G.F., 1974. A method of assessing woodland flora for conservation using indicator species. Biol. Conserv. 6, 239-245.

Pierce, S., Negreiros, D., Cerabolini, B.E.L., et al., 2017. A global method for calculating plant CSR ecological strategies applied across biomes world-wide. Funct. Ecol. 31 (2), 444-457.

Polyakova, M.A., Dembicz, I., Becker, T., et al., 2016. Scale- and taxon-dependent patterns of plant diversity in steppes of Khakassia, South Siberia (Russia). Biodiv. Conser 25, 2251-2273.

Rodrigues, A.S.L., Brooks, T.M., 2007. Shortcuts for biodiversity conservation planning: the effectiveness of surrogates. Annu. Rev. Ecol. Evol. Systemat. 38, 713-737.

Rooney, T.P., Wiegmann, S.M., Rogers, D.A., et al., 2004. Biotic impoverishment and homogenization in unfragmented forest understory communities. Conserv. Biol. 18, 787-798.

Scolastri, A., Cancellieri, L., Iocchi, M., et al., 2017. Old coppice vs high forest: the impact of beech forest management in plant species diversity in central Appennines (Italy). J. Plant Ecol. 10 (2), 271-280.

Slaviero, A., Del Vecchio, S., Pierce, S., Fantinato, E., Buffa, G., 2016. Plant community attributes affect dry grassland orchid establishment. Plant Ecol. 217, 1533-1543.

Steffan-Dewenter, I., Tscharntke, T., 2000. Butterfly community structure in fragmented habitats. Ecol. Lett. 3, 449-456.

Svensson, J.R., Lindegarth, M., Pavia, H., 2010. Physical and biological disturbances in teract differently with productivity: effects on floral and faunal richness. Ecology 91, 3069-3080.

Tilman, D., 1994. Competition and biodiversity in spatially structured habitats. Ecology 75, 2-16.

Tilman, D., Fargione, J., Wolff, B., et al., 2001. Forecasting agriculturally driven global environmental change. Science 292, 281-284.

Tilman, D., May, R.M., Lehman, C.L., Nowak, M.A., 1994. Habitat destruction and the extinction debt. Nature 371, 65-66.

Turner, I.M., Chua, K.S., Ong, J.S.Y., et al., 1996. A century of plant species loss from an isolated fragment of lowland tropical rain forest. Conserv. Biol. 10, 1229-1244.

Turner, M.G., Gardner, R.H., O'Neill, R.V., 2001. Landscape Ecology in Theory and Practice: Pattern and Process. Springer-Verlag, New York, USA.

Turtureanu, P.D., Palpurina, S., Becker, T., et al., 2014. Scale- and taxon-dependent biodiversity patterns of dry grassland vegetation in Transylvania. Agric. Ecosyst. Environ. $182,15-24$.

Van Dobben, W., Lowe-McDonnel, R., 1975. Unifying Concepts in Ecology: Report of the Plenary Session of the First International Congress of Ecology. Junk W, September 8-14, Hague, Wageningen, The Netherlands.

Venables, W.N., Ripley, B.D., 2002. Modern Applied Statistics with S, fourth ed Springer, New York.

Verheyen, K., Honnay, O., Motzkin, G., et al., 2003. Response of forest plant species to land-use change: a life-history trait-based approach. J. Ecol. 91, 563-577.

Wei, Y., Hoganson, H.M., 2005. Landscape impacts from valuing core area in national forest planning. For. Ecol. Manag. 218, 89-106.

Wiens, J.A., 1989. Spatial scaling in ecology. Funct. Ecol. 3, 385-397.

$\mathrm{Wu}, \mathrm{J}$., 2004. Effects of changing scale on landscape pattern analysis: scaling relations. Landsc. Ecol. 19, 125-138. 